\title{
POTENSI EKSTRAK ETANOL RIMPANG JERINGAU (Acorus calamus L.) SEBAGAI SPASMOLITIK
}

\author{
Marihot Pasaribu*, Nataniel Tandirogang, Sjarif Ismail, Swandari Paramita, \\ Agustina Rahayu Magdaleni, Hary Nugroho \\ Fakultas Kedokteran Universitas Mulawarman Samarinda Kalimantan Timur \\ *Corresponding author email: marihotp@gmail.com
}

\begin{abstract}
Pain due to smooth muscle stiffness can occur in various circumstances of patients, ranging from normal circumstances such as menstrual pain, to a pathological condition of gastrointestinal infections. To overcome the pain it can be given medication to reduce muscle stiffness as spasmolytics, but there are side effects of the drug. Thus, the need for developing new spasmolytics drugs based on medicinal herbs with fewer side effects. This study was conducted to examine the potential of rhizome extract of jeringau (Acorus calamus L.) that is traditionally used by Dayak tribe to heal upset stomach. Spasmolytic activity of plant extracts tested with isolates organ methods of guinea pig ileum induced by histamine. Result of the study showed $0.3 \mathrm{mg} / \mathrm{ml} \mathrm{A}$. calamus rhizomes extract could decrease ileum contraction better than papaverine $0.03 \mathrm{mg} / \mathrm{ml}(p=0.00)$. The conclusion of this study is rhizome extract of jeringau (A. calamus) has the potential to be used as spasmolytics in treatment of health problems caused by smooth muscle contraction.
\end{abstract}

Keywords: Acorus calamus, spasmolytic, ileum isolated organ

\section{ABSTRAK}

Rasa nyeri akibat kekakuan otot polos dapat terjadi pada berbagai keadaan pasien, mulai dari keadaan normal seperti nyeri haid, hingga keadaan patologis seperti infeksi saluran pencernaan. Untuk mengatasi rasa nyeri maka dapat diberikan obat spasmolitik untuk mengurangi kekakuan otot polos, namun terdapat efek samping dari obat tersebut. Dengan demikian maka perlu pengembangan obat baru spasmolitik berbasis tumbuhan obat dengan efek samping yang lebih sedikit. Penelitian ini dilakukan untuk menguji potensi ekstrak rimpang jeringau (Acorus calamus L.) yang secara tradisional digunakan etnis Dayak sebagai obat sakit perut. Aktivitas spasmolitik ekstrak tumbuhan diuji dengan metode isolat organ ileum marmut yang diinduksi dengan histamin. Aktivitas spasmolitik A. calamus $0,3 \mathrm{mg} / \mathrm{ml}$ mampu menurunkan tonus ileum marmut lebih baik dibanding papaverin $0,03 \mathrm{mg} / \mathrm{ml}(\mathrm{p}=0,00)$. Kesimpulan penelitian ini adalah ekstrak rimpang jeringau $(A$. calamus) berpotensi digunakan sebagai spasmolitik dalam penatalaksanaan masalah kesehatan akibat kontraksi otot polos.

Kata kunci: Acorus calamus, spasmolitik, isolat organ ileum

$$
\text { Submit : } 4 \text { April } 2017
$$

Accepted:8 May 2017

DOI: https://doi.org/10.25026/jsk.v1i7.53

\section{PENDAHULUAN}

Obat spasmolitik adalah obat yang mengurangi peningkatan tonus otot abnormal atau spasme tanpa menyebabkan paralisis. Kontraksi otot yang intermiten selalu berhubungan dengan rasa nyeri pada pasien (Hitner dan Nagle, 2012). Jenis obat-obatan yang termasuk obat spasmolitik antara lain adalah hiosin butilbromida dan papaverin. Indikasi pemberian obat spasmolitik adalah gangguan spasme pada saluran pencernaan (kolik lambung dan usus), saluran empedu (kolik batu empedu), saluran kemih (kolik batu ginjal) dan sistem reproduksi perempuan (dismenorea) (Brunton et al, 2006). Masyarakat di Indonesia biasa 
menyimpan obat spasmolitik di rumah seperti hiosin butilbromida dan papaverin, untuk mengilangkan keluhan kejang perut (Raini dan Isnawati, 2016).

Namun demikian terdapat beberapa efek samping dari obat spasmolitik yang saat ini umum dipakai di dunia kedokteran. Efek samping tersebut adalah xerostomia (kekeringan pada mulut), dishidrosis (kekeringan pada kulit), takikardi atau bradikardi, aritmia jantung, palpitasi, retensi urin, konstipasi, gangguan penglihatan, reaksi alergi dan reaksi kulit (MIMS, 2016).

Berdasarkan hal tersebut, maka upaya pencarian obat spasmolitik baru perlu dilakukan. Salah satu sumber obat spasmolitik baru adalah tumbuhan obat yang berasal dari alam. Penelitian terhadap pengobatan tradisional pada masyarakat di berbagai tempat menunjukkan adanya tumbuhan yang digunakan untuk menghilangkan sakit perut. Penelitian juga menunjukkan bahwa beberapa tumbuhan obat memiliki efek mengurangi kekakuan otot polos. Hal ini menunjukkan adanya potensi tumbuhan obat sebagai spasmolitik (Amit dan Vandana, 2013).

Salah satu tumbuhan obat yang memiliki potensi efek spasmolitik adalah Acorus calamus L. Tumbuhan ini termasuk dalam famili Acoraceae. Tumbuhan ini tersebar di Asia Selatan hingga Tenggara. Tumbuhan ini dikenal dengan nama jeringau dalam bahasa Indonesia atau sweet flag dalam bahasa Inggris. A. calamus digunakan masyarakat lokal sebagai obat diare (Rajputa et al, 2014). Sementara itu etnis Dayak di Kalimantan Utara menggunakan $A$. calamus untuk mengobati sakit perut (Ismail et al, 2015). Berdasarkan hal tersebut diatas maka penelitian ini bermaksud untuk melihat aktivitas spasmolitik ekstrak rimpang A. calamus dengan menggunakan isolat organ ileum .

\section{METODE PENELITIAN}

\section{Waktu dan Tempat}

Penelitian dilakukan pada bulan Mei hingga Oktober 2016. Lokasi pengambilan sampel tumbuhan obat dilakukan di Kabupaten Malinau, Kalimantan Utara. Identifikasi tumbuhan obat dilakukan oleh Laboratorium Dendrologi, Fakultas Kehutanan Universitas Mulawarman. Pengolahan sampel tumbuhan obat hingga proses ekstraksi dan uji aktivitas spasmolitik dengan isolat organ ileum dilakukan di Laboratorium Farmakologi, Fakultas Kedokteran Universitas Mulawarman. Penelitian ini telah memperoleh kelayakan etik dari Komisi Etik Penelitian Kedokteran dan Kesehatan, Fakultas Kedokteran Universitas Mulawarman.

\section{Pembuatan Ekstrak Tumbuhan Obat}

Ekstraksi yang dilakukan adalah dengan metode maserasi seperti yang dijelaskan dalam Farmakope Herbal Indonesia (Depkes RI, 2008). Sebanyak kurang lebih 2 kilogram simplisia dari rimpang A. calamus, yang telah memenuhi kriteria pemilihan, dipotong kecil-kecil, dicuci sampai bersih, dikeringkan sampai kadar air kurang dari $10 \%$. Simplisia yang sudah kering diserbuk sampai ukuran 4/18 dengan blender kemudian dimaserasi dengan etanol p.a dengan perbandingan 1:10 (satu bagian simplisia: 10 bagian pelarut). Rendam selama 6 jam kemudian diaduk dengan shaker orbital dengan kecepatan $20 \mathrm{rpm}$ selama 10 menit pada suhu kamar, kemudian diamkan selama 18 jam.

Maserasi dilakukan selama 3 x 24 jam lalu disaring dengan menggunakan kertas saring Whatman, maserasi diulang dengan pelarut etanol yang baru dan proses ini diulang sebanyak dua kali. Seluruh cairan ekstraksi setelah disaring dan dikumpulkan dimasukan dalam 
vakum rotavapor suhu $50{ }^{\circ} \mathrm{C}$ untuk dilakukan pemekatan. Ekstrak pekat yang didapat kemudian dikeringkan lebih lanjut dengan dimasukan dalam desikator yang berisi silika dalam oven suhu $50{ }^{\circ} \mathrm{C}$. Setelah didapatkan ekstrak kering ditimbang untuk dapat dihitung rendemennya. Ekstrak kering disimpan dalam kulkas $-4{ }^{\circ} \mathrm{C}$ sebelum dilakukan penelitian lebih lanjut untuk uji aktivitas spasmolitik.

\section{Uji aktivitas spasmolitik dengan isolat organ ileum}

Penelitian ini menggunakan isolat organ ileum . Eksplorasi tempat kerja suatu obat pada saluran cerna sebagai spamolitik dapat menggunakan isolat organ ileum marmut. Organ ileum relatif lebih tahan terhadap trauma dan kontraksinya lebih kuat daripada jejenum dan duodenum sehingga memudahkan untuk pengamatan. Usus marmut sangat sensitif terhadap induksi histamin melalui reseptor $\mathrm{H}_{1}$ dan menyebabkan peningkatan tonus kontraksi usus seperti pada manusia sehingga dapat digunakan sebagai model untuk pengujian obat baru untuk spasmolitik secara in vitro. Histamin diberikan untuk menginduksi spasme dari isolat organ ileum marmut. Histamin dapat menyebabkan peningkatan kontraksi usus (Trevor et al, 2013). Marmut yang digunakan berumur 4-6 bulan dengan berat 250-450 gram dari Laboratorium Farmakologi Fakultas Kedokteran Universitas Mulawarman yang dipelihara dengan kondisi terkontrol.

Satu hari sebelum penelitian marmut dipuasakan semalam. Marmut dibunuh dengan penyuntikan anestesi berlebihan ketamin. Abdomen dibuka dan dilakukan preparasi isolat organ ileum marmut seperti yang dijelaskan oleh Vogel dan Vogel (1997). Segmen ileum sepanjang 2,5 cm dipotong dan dimasukan dalam organ bath $25 \mathrm{ml}$ berisi larutan
Kreb 's-Henselheit ( $\mathrm{pH} 7,4$ dan suhu $37^{\circ} \mathrm{C}$ yang dialiri gas carbogen). Salah satu ujung dipasang transduser isotonik dengan beban awal 0,5 gram. Transduser dihubungkan dengan alat amplifikasi perekam digital $A D$ Instrument dengan Program Chart v.5. Perubahan tonus kontraksi ileum pada komputer tercatat dalam gram.

Sebelum diberi perlakuan, dibiarkan untuk ekuilibrasi selama 60 menit dalam larutan Kreb's-Henselheit agar keadaan menjadi stabil dan setiap 10 menit sekali larutan diganti dengan larutan Kreb'sHenselheit yang baru. Setelah stabil, kontraksi ileum marmut diberi histamin 40 $\mathrm{nM}$, untuk menimbulkan respons kontraksi yang meningkat, selanjutnya diberi papaverin untuk melihat respons spasmolitik. Jika ileum marmut mengalami peningkatan tonus setelah pemberian histamin dan penurunan tonus setelah pemberian papaverin maka ileum tersebut dinyatakan siap untuk uji aktivitas spsmolitik dengan ekstrak tumbuhan.

Ileum marmut yang sudah stabil dibuat kontraksi dengan histamin. Setelah mencapai kontraksi yang maksimal selama satu menit, selanjutnya diberi bahan ekstrak, kemudian dibiarkan sampai respons penurunan tonus ileum mencapai batas maksimal. Larutan diganti sebanyak tiga kali berturut-turut dan setiap 10 menit sekali sampai keadaan stabil dan siap untuk dilakukan percobaan dosis berikutnya. Hasil yang didapat dinyatakan dalam persen penurunan tonus usus. Pengulangan dilakukan 3 kali pada setiap ekstrak tumbuhan obat.

\section{Analisis Statistik}

Pengolahan data dilakukan dengan SPSS Statistics 20.0. Homogenitas dan normalitas data diuji dengan Test of Homogeneity of Variance (Levene Statistic) dan Test of Normality (Kolmogorov-Smirnov). Data yang 
terdistribusi normal dan bervarian homogen dianalisis secara statistik parametrik menggunakan Analysis of Variance (ANOVA). Data yang tidak terdistribusi normal dan tidak bervarian homogen dianalisis secara statistik non parametrik menggunakan uji Kruskal Wallis. Perbedaan dikatakan signifikan jika $\mathrm{p}<0.05$.

\section{HASIL DAN PEMBAHASAN}

Hasil penelitian menunjukkan aktivitas spasmolitik ekstrak etanol rimpang A. calamus pada konsentrasi 0,3 $\mathrm{mg} / \mathrm{ml}$ mampu menurunkan tonus ileum marmut lebih baik dibanding dengan papaverin $0,03 \mathrm{mg} / \mathrm{ml}$ dan secara statistik ada perbedaan bermakna antara keduanya $(\mathrm{p}=0,00)$, seperti yang terlihat pada Gambar 1. Jika dibandingkan dengan DMSO (kontrol negatif) terdapat perbedaan yang sangat bermakna $(\mathrm{p}=0,001)$. Tampak bahwa persentase penurunan tonus ileum oleh $A$. calamus lebih besar dibandingkan papaverin. Bahkan pada konsentrasi $0,03 \mathrm{mg} / \mathrm{ml} A$. calamus sudah mampu menurunkan tonus lebih dari 90\%. (konsentrasi papaverin yang digunakan lebih rendah 0,1 dibandingkan dengan ekstrak yang diuji). Ada perbedaan bermakna antara $A$. calamus $0,03 \mathrm{mg} / \mathrm{ml}$ dengan papaverin $(\mathrm{p}=0,00)$, tetapi pada konsentrasi $A$. calamus $3 \mathrm{mg} / \mathrm{ml}$ tidak ada perbedaan $(\mathrm{p}=0,12)$.

Efek maksimal (E max) ekstrak rimpang A. calamus lebih tinggi daripada kontrol negatif. Hal ini menunjukkan bahwa ekstrak rimpang $A$. calamus dapat menurunkan tonus ileum marmut. Ekstrak rimpang A. calamus memberikan $\mathrm{E}$ max yang lebih tinggi dari pada kontrol positif, seperti yang terlihat pada Gambar 2 . Demikian halnya untuk $\mathrm{EC}_{50}$, ekstrak rimpang A. calamus memiliki nilai lebih kecil daripada kontrol negatif dan positif, seperti yang terlihat pada Gambar 3. Hal ini menunjukkan bahwa $A$. calamus memiliki efikasi sangat besar dan poten (dengan konsentrasi yang kecil sudah dapat menimbulkan efek 50\%) sebagai spasmolitik. Efikasi berhubungan dengan E maks dan potensi suatu obat berhubungan dengan niai EC 50 (Katzung, 2009).

Hasil penelitian menunjukkan adanya aktivitas spasmolitik oleh ekstrak etanol rimpang A. calamus jika dibandingkan dengan papaverin sebagai kontrol positif. Taksonomi A. calamus adalah sebagai berikut.

$\begin{array}{ll}\text { Kerajaan } & \text { : Plantae } \\ \text { Kelas } & \text { : Angiosperms } \\ \text { Subkelas } & \text { : Monocots } \\ \text { Ordo } & : \text { Acorales } \\ \text { Famili } & : \text { Acoraceae } \\ \text { Genus } & : \text { Acorus } \\ \text { Spesies } & : \text { Acorus calamus L. }\end{array}$

Sinonim tumbuhan ini adalah Acorus angustatus Raf., Acorus angustifolius Schott, Acorus aromaticus Gilib., Acorus belangeri Schott., Acorus calamus var. angustifolius (Schott) Engl., Acorus calamus var. belangeri (Schott) Engl., Acorus calamus var. calamus, Acorus calamus f. submersa Gluck, Acorus calamus var. verus L., Acorus calamus var. vulgaris L., Acorus calamusaromaticus Clairv., Acorus casia Bertol., Acorus commersonii Schott, Acorus commutatus Schott, Acorus elatus Salisb., Acorus europaeus Salisb., Acorus flexuosus Raf., Acorus floridanus Raf., Acorus griffithii Schott, Acorus nilghirensis Schott, Acorus odoratus Lam., Acorus terrestris Spreng., Acorus undulatus Stokes, Acorus verus (L.) Raf., Acorus verus Garsault, dan Calamus aromaticus Garsault (The Plant List, 2013). 


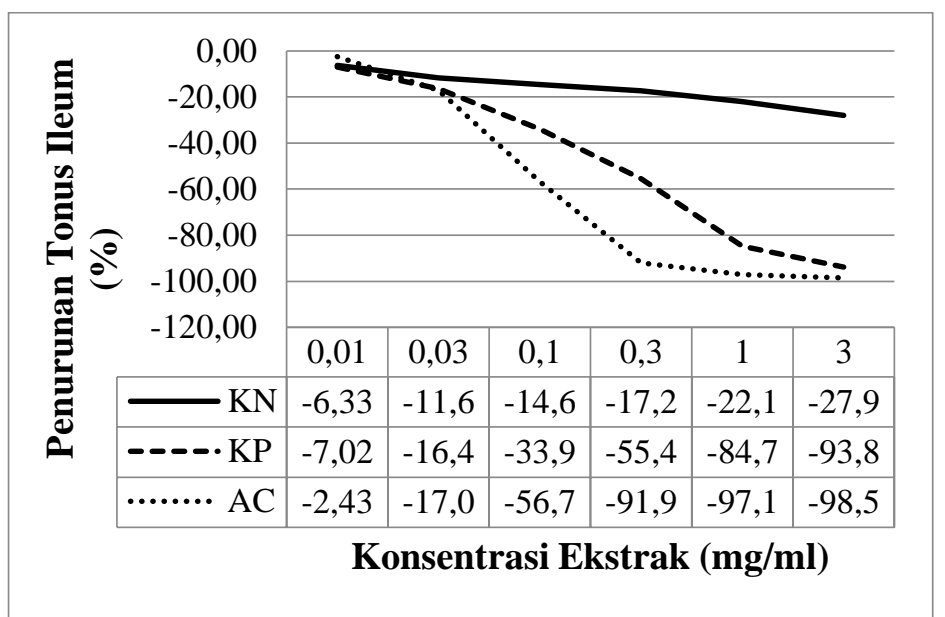

Gambar 1. Grafik perbedaan penurunan tonus ileum marmut antara A. calamus (AC), papaverin sebagai kontrol positif (KP) dan DMSO sebagai kontrol negatif $(K N)$ pada isolat organ ileum marmut.

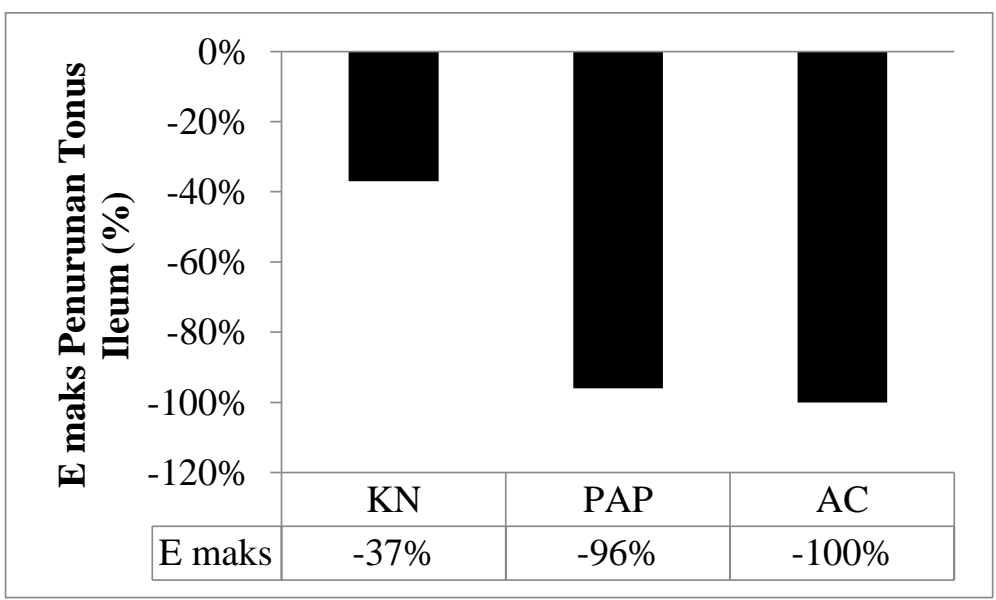

Gambar 2. Grafik perbandingan E maks antara kontrol negatif $(K N)$, papaverin (PAP), dan ekstrak A. calamus $(A C)$

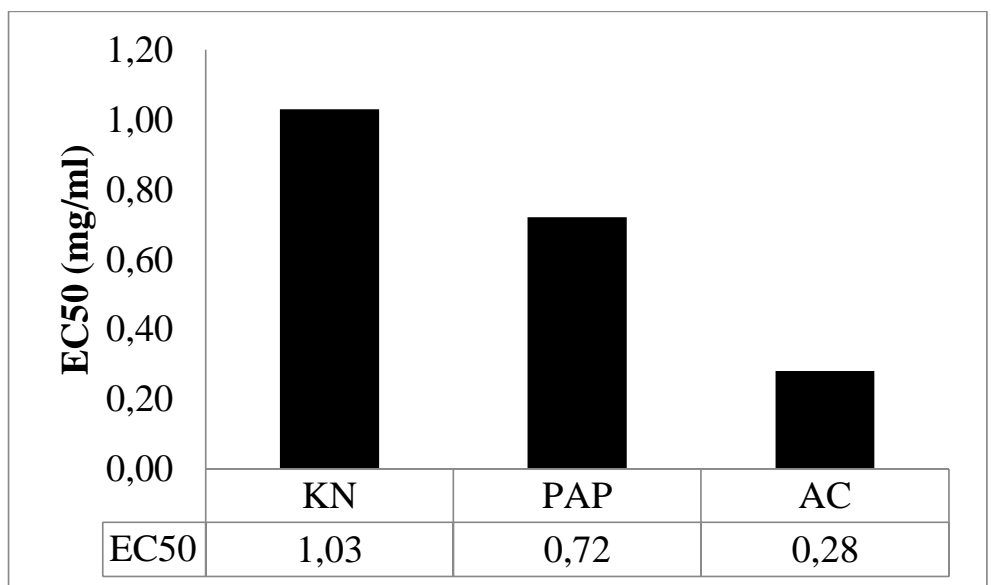

Gambar 3. Grafik perbandingan $E C_{50}$ antara kontrol negatif $(K N)$, papaverin $(P A P)$, dan ekstrak A. calamus $(A C)$ 
Minyak esensial A. calamus mengandung konstitusi aktif $\alpha$-asarone dan $\beta$-asarone (Yende et al, 2008). Penelitian pada ileum, uterus, otot polos bronkus, cincin trakea dan pembuluh darah menunjukkan adanya aktivitas antispasmodik dan relaksasi dari minyak esensial dan komponen $\beta$-asarone dari rimpang A. calamus (Amit dan Vandana, 2013).

Sebuah penelitian menunjukkan efek antispasmodik dan antidiare dari $A$. calamus. Pada penelitian dengan menggunakan isolat organ jejunum dari kelinci, ditemukan bahwa ekstrak $A$. calamus menyebabkan inhibisi spontan kontraksi yang diinduksi kadar $\mathrm{K}(+)$ tinggi, sehingga menimbulkan aktivitas spasmolitik yang dimediasi blokade kanal kalsium (Singh et al, 2011).

Penelitian lain menunjukkan bahwa ekstrak A. calamus mengandung konstituen kimia dengan kemampuan mengeblok kanal kalsium yang berperan dalam aktivitas spasmolitik. Fraksi etil asetat dan n-heksan dari ekstrak $A$. calamus menunjukkan efek spasmolitik pada isolat organ jejunum kelinci (Ganjewala dan Srivastava, 2011).

Penelitian pada isolat organ jejunum kelinci, ekstrak $A$. calamus menyebabkan inhibisi kontraksi spontan $\left(\mathrm{EC}_{50}=0,42\right.$ $\mathrm{mg} / \mathrm{ml}$ ) maupun yang diinduksi kalium $\left(\mathrm{EC}_{50}=0,13 \mathrm{mg} / \mathrm{ml}\right)$, yang mengakibatkan aktivitas spasmolitik yang dimediasi blokade jalur kalsium oleh calcium channel blocker (CCB). Penelitian tersebut menunjukkan bahwa efek spasmolitik ekstrak A. calamus dimediasi oleh adanya konstituen yang menyerupai $\mathrm{CCB}$, yang terkonsentrasi dalam fraksi nheksan. Hasil penelitian ini sejalan dengan penggunaan A. calamus secara tradisional untuk gangguan pencernaan seperti nyeri kolik (Rajputa et al, 2014).

\section{KESIMPULAN}

Hasil penelitian ini menunjukkan bahwa ekstrak etanol rimpang A. calamus berpotensi sebagai spasmolitik untuk mengurangi rasa nyeri akibat kekakuan otot polos. Perlu adanya penelitian lanjutan agar $A$. calamus dapat dikembangkan sebagai sumber obat spasmolitik baru berbasis tumbuhan obat.

\section{DAFTAR PUSTAKA}

[1]. Amit K, Vandana V. (2013). Medicinal properties of Acorus calamus. Journal of Drug Delivery \& Therapeutics. 3(3): 143144.

[2]. Brunton LL, Lazo JS, Parker KL. (2006). Goodman and Gilman's The Pharmacological Basis of Therapeutics. Eleventh edition. McGrawHill. New York.

[3]. Departemen Kesehatan RI. (2008). Farmakope Herbal Indonesia. Edisi Pertama. Departemen Kesehatan RI. Jakarta.

[4]. Ganjewala D, Srivastava AK. (2011). An update on chemical composition and bioactivities of Acorus species. Asian Journal of Plant Species. 10(3): 182-189.

[5]. Hitner H, Nagle B. (2012). Pharmacology An Introduction. Sixth Edition. McGraw Hill. New York.

[6]. Ismail S, Suwasono RA, Supriyoko W, Kuswanto H, Paryono P. (2015). Laporan Penelitian Riset Eksplorasi Pengetahuan Lokal Etnomedisin dan Tumbuhan Obat di Indonesia Berbasis Komunitas di Suku Abai, Kabupaten Malinau, Propinsi Kalimantan Utara. Badan Penelitian dan Pengembangan Kesehatan. Kementerian Kesehatan RI.

[7]. Katzung BG. (2009). Basic and Clinical Pharmacology. Eleventh Edition. McGrawHill. San Fransisco.

[8]. MIMS. (2016). MIMS Referensi Obat. Edisi Tujuh Belas. Bhuana Ilmu Populer. Jakarta.

[9]. Raini M, Isnawati A. (2016). Profile of Diare Medication Stored in Households in Indonesia Year 2013. Media Litbangkes. 26(4): 227-234.

[10]. Rajputa SB, Tongeb MB, Karuppayila SM. (2014). An overview on traditional uses and pharmacological profile of Acorus calamus Linn. (Sweet flag) and other Acorus species. Phytomedicine. 21: 268-276. 
[11]. Singh R, Sharma PK, Malviya R. (2011). Pharmacological Properties and Ayurvedic Value of Indian Buch Plant (Acorus calamus): A Short Review. Advances in Biological Research. 5(3): 145-154.

[12]. The Plant List. (2013). Version 1.1. http://www.theplantlist.org

[13]. Trevor AJ, Katzung BG, Kruidering-Hall M, Masters SB. (2013). Pharmacology Examination and Board Review. Tenth Edition. McGraw Hill Medical. New York.
[14]. Vogel HG, Vogel WH. (1997). Drug discovery and evaluation: pharmacological assays. Chapter J: Activity of the gastrointestinal tract: Gut motility: Isolated ileum (MAGNUS technique). 496-498. Springer-Verlag. Berlin.

[15]. Yende SR, Harle UN, Rajgure DT, Tuse TA, Vyawahare NS. (2008). Pharmacological profile of Acorus calamus: An Overview. Pharmacognosy Reviews. 2(4): 22-26. 